Article - Human and Animal Health

\title{
Anti-inflammatory and Antioxidant Effects of the Microalga Pediastrum boryanum in Carrageenan- Induced Rat Paw Edema
}

Marília Garcez Corrêa da Silva ${ }^{1}$

https://orcid.org/0000-0003-1448-6200

Mariana Appel Hort ${ }^{1,2}$

https://orcid.org/0000-0001-5877-3506

Gabriela Hädrich ${ }^{1}$

https://orcid.org/0000-0002-2360-8882

Lidiane Dal Bosco 3

https://orcid.org/0000-0002-6090-5376

Gustavo Richter Vaz ${ }^{1}$

https://orcid.org/0000-0003-0951-801X
Ronan Adler Tavella ${ }^{1}$

https://orcid.org/0000-0003-2436-4186

\author{
Eliana Badiale-Furlong ${ }^{4}$ \\ https://orcid.org/0000-0002-5864-8796
}

Flavio Manoel Rodrigues da Silva Júnior ${ }^{1,2}$

https://orcid.org/0000-0002-7344-4679

Cristiana Lima Dora ${ }^{1,2}$

https://orcid.org/0000-0002-9198-437X

Ana Luiza Muccillo-Baisch ${ }^{1,2^{\star}}$

https://orcid.org/0000-0002-9475-6698

\section{Michelle Maidana Altenhofen da Silva ${ }^{1}$}

https://orcid.org/0000-0001-8855-438X

${ }^{1}$ Federal University of Rio Grande, Posgraduate Program in Health Sciences, Faculty of Medicine, Rio Grande, Rio Grande do Sul, Brazil; ${ }^{2}$ Federal University of Rio Grande, Institute of Biological Sciences, Rio Grande, Rio Grande do Sul, Brazil; ${ }^{3}$ Federal University of Pampa, Uruguaiana, Rio Grande do Sul, Brazil; ${ }^{4}$ Federal University of Rio Grande, Postgraduate Program in Food Engineering and Science, School of Chemistry and Food, Rio Grande, Rio Grande do Sul, Brazil.

Editor-in-Chief: Alexandre Rasi Aoki

Associate Editor: Acácio Antonio Ferreira Zielinski

Received: 2020.11.30; Accepted: 2021.07.28.

${ }^{*}$ Correspondence: anabaisch@gmail.com; Tel.: +55-53- 32935170 (A.L.M.B.).

\section{HIGHLIGHTS}

- P. boryanum as a source of bioactive compounds.

- $\quad$ P. boryanum biomass present anti-inflammatory properties.

- Phenolic compounds from $P$. boryanum are anti-inflammatory and antioxidants.

Abstract: The potential use of microalgae in health has been the aim of different studies in the last years. This study investigated anti-inflammatory and antioxidant properties of three different extracts of green microalga Pediastrum boryanum in an acute inflammation model in rats. Rats were treated intraperitoneally with lyophilized biomass, the phenolic compounds and the extracellular extracts of $P$. boryanum before the induction of paw edema by the intraplantar injection of carrageenan. The edema and the levels of interleukin$1 \beta$ and tumor necrosis factor- $\alpha$ were determined in the hind paw. Oxidative stress markers were analyzed in 
the liver and hepatic toxicity and genetic damage was evaluated in the blood. The results demonstrated that the three extracts of $P$. boryanum exhibited pronounced anti-oedematous property and decreased the levels of cytokines. The best results were provided by the phenolic compounds extract, that contains gallic, chlorogenic, protocathecuic and vanillic acid. A reduction in lipid peroxidation was observed after the treatment with lyophilized biomass and the extracellular extract improved the total antioxidant capacity of the liver. Moreover, no DNA damage and hepatic toxicity were observed after administration of $P$. boryanum extracts. In conclusion, these results suggest that $P$. boryanum can be an important source of antiinflammatory compounds.

Keywords: microalga; inflammation; oxidative stress; phenolic compounds; biomass.

\section{GRAPHICAL ABSTRACT}

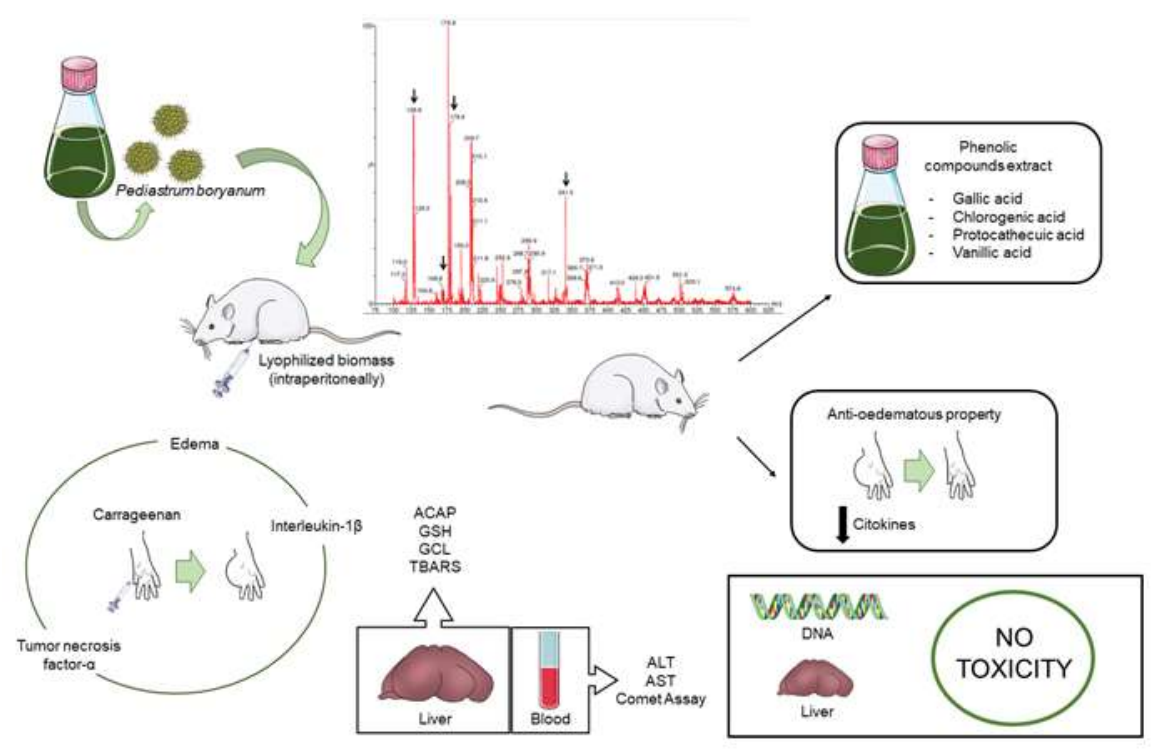

\section{INTRODUCTION}

Algae are photosynthetic eukaryotes that range from a single cell form to a multicellular organism. They are commonly found in the sea, rivers, lakes, ponds, and tree trunks. Algae are divided into microalgae (microscopic algae) and macroalgae, and the difference focuses on their size. The macroalgae are multicellular and are known as seaweed, and microalgae are uni or multicellular organisms that may be organized in colonies and are part of the phytoplankton [1]. Investigations about microalgae started for their nutritional and traditional health benefits, taking into account that some marine algae are edible and abundant in some areas and have been used as food [2].

Microalgae have been the aim of different studies in the last years. The biotechnology of production has made major advances and the study on cultivation conditions or nutrient availability favoring the synthesis of different metabolites, like polyunsaturated fatty acids, phenolic compounds, and polysaccharides [3-5]. The pharmacological properties of the microalgae such as diabetic prevention, anti-carcinogenic, antinociceptive and anti-inflammatory have been demonstrated using in vitro and in vivo experimental models [6-8]. The microalga Chlamydomonas, Spirulina, and Chlorella have shown anti-inflammatory and antioxidant properties in different experimental conditions [6,9-12].

Some species of microalgae have been extensively investigated, although there are hundreds of others that have their pharmacological potential still little explored. In this context, we highlight the species Pediastrum boryanum (Chlorococcales). Recently, we demonstrated that $P$. boryanum is a potentially rich source of antioxidants, especially phenolic compounds [13]. Moreover, the acute oral toxicity of freeze-dried biomass obtained from $P$. boryanum was evaluated according to OECD protocol 423, and it was classified as 'Minimal Toxicity or Secure' [14]. Considering previous studies that demonstrate that this microalga is an important source of antioxidant compounds and that it has low toxicity in rodents, this study aims to investigate the anti-inflammatory and antioxidant activity of $P$. boryanum in a carrageenan-induced rat model of inflammation. 


\section{MATERIAL AND METHODS}

\section{Chemical and reagents}

2,2'-azobis 2 methylpropionamidine dihydrochloride (ABAP), $\lambda$-carrageenan, adenosine triphosphate (ATP), borate, butylated hydroxytoluene (BHT), cysteine, ethylenediaminetetraacetic acid (EDTA), fetal bovine serum, glutamate, glutathione (GSH), low melting agarose (LMA), normal melting agarose (NMA), serine, tetramethylbenzidine (TMB), Tris- $\mathrm{HCl}$ (Trizma hydrochloride) and Tween $\AA 20$ were obtained from Sigma-Aldrich (Saint Louis, MO, USA). 2', 7'-Dichlorofluorescein-diacetate $\left(\mathrm{H}_{2} \mathrm{DCF}-\mathrm{DA}\right)$ was purchased from Invitrogen (Waltham, MA, USA). Carboxymethyl cellulose (CMC) was supplied by DEG (São Paulo, SP Brazil). Diclofenac sodium (Voltaren $\AA$ ) was obtained from Novartis (Basel, Switzerland). Tetramethylbenzidine (TMB) Substrate Reagent Set was purchased from BD Biosciences (San Jose, CA, USA). Other chemicals and reagents were of analytical grade.

\section{Culture Conditions and Sample Preparation}

The microalga Pediastrum boryanum (Chlorophyceae, Chlorococcales) (Turpin) was obtained from Merin Lagoon, located in the Rio Grande do Sul state, Brazil $\left(32^{\circ} 52^{\prime} 44^{\prime \prime} \mathrm{S}, 52^{\circ} 46^{\prime} 04^{\prime \prime}\right.$ W). It was isolated on a microscope (mod. CX41F; Olympus, Tokyo, Japan) by a micropipette, as described by [15], and the strain was deposited in the Culture Collection of Freshwater Microalgae at the Institute of Biological Science/Universidade Federal do Rio Grande - FURG.

Axenic stock culture of $P$. boryanum was cultivated in BG11 medium modified with extra $0.4 \mathrm{~g} / \mathrm{L}$ of $\mathrm{NaHCO}_{3}\left(\mathrm{MBG} 11\right.$ medium) under a $12 \mathrm{~h}$ light/dark cycle $\left(27 \mu \mathrm{mol} \cdot \mathrm{m}^{-2} \cdot \mathrm{s}^{-1}\right), 30^{\circ} \mathrm{C}$, in a $2.0 \mathrm{~L}$ Erlenmeyer flask [13]. The cultures were air-mixed by sterile air injection. The initial biomass concentration of $P$. boryanum was $0.2 \mathrm{~g} / \mathrm{L}$. The growth pattern of the microalgae was monitored daily until the microalgae reached the stationary phase, as established when the biomass concentration remained the same for three consecutive days.

For sample preparation, the culture was centrifuged (NI1814, Nova Instruments, Piracicaba, Brazil) in $50 \mathrm{~mL}$ falcon tubes (4000 rpm, $5 \mathrm{~min}$, room temperature) and the supernatant collected and used as an extracellular sample). The pellet of the microalga was then lyophilized (Liotop L101, São Carlos, Brazil) for $48 \mathrm{~h}$. Two different samples were prepared from the lyophilized biomass: the first sample of the lyophilized biomass was suspended in carboxymethyl cellulose (CMC $0.5 \%$ ) to guarantee a homogeneous suspension of the microalgae $(0.1 \mathrm{~g} / \mathrm{mL})$ for intraperitoneal injection. The second sample consisted of the extraction of phenolic compounds from the lyophilized biomass according to Souza and coauthors [16].

\section{Characterization of free phenolic acids}

Phenolic acids present in the $P$. boryanum lyophilized biomass were analyzed by a Shimadzu Ultrafast Liquid Chromatography (UFLC) system equipped with a C18 5u 110A column (5mmx4.6x250mm). The mobile phase consisted of an isocratic elution using aqueous acetic acid $(1 \%, \mathrm{pH} 3)$ and methanol $(1: 1, \mathrm{v} / \mathrm{v})$ at a flow rate of $0.9 \mathrm{~mL} \cdot \mathrm{min}^{-1}(103 \mathrm{kgf})$, with a total running time of $30 \mathrm{~min}$ [17]. The compounds were identified by comparison of their retention time (tR) and spectroscopic data (UV and 1H- and 13C-NMR) with gallic, protocatechuic, chlorogenic, hydroxybenzoic, caffeic, vanillic, and ferulic acid. The determination was done in the free phenolic extract from $P$. boryanum with a UV-visible detector at 280 and $320 \mathrm{~nm}$ equipped with a Phenomenex column C-18 $5 \mu 110$ A (5 mm x $4.6 \mathrm{~mm} \times 250 \mathrm{~mm})$. The phenolic acids were identified comparing the retention time of the sample to the standards of choice.

Mass spectrometry was performed in a Micromass ${ }^{\circledR}$ Four Micro ${ }^{\mathrm{TM}}$ API Waters with API source (Waters, Milford, MA, USA), ionization source Electrospray, and mass analyzer triple quadrupole. The infusion of samples was done directly in the mass spectrometer and was performed at a flow rate of $10 \mathrm{~L} / \mathrm{min}$ in full scan mode to scan from $\mathrm{m} / \mathrm{z} 100$ to 600 . The conditions employed were source temperature of $120^{\circ} \mathrm{C}$, desolvation gas temperature of $400^{\circ} \mathrm{C}$. The nitrogen gas flow to desolvation of the sample and the cone of the sample was 500 and $100 \mathrm{~L} / \mathrm{h}$, respectively. The capillary voltage was $3 \mathrm{kV}$ and the cone voltage $20 \mathrm{~V}$.

\section{Animals}

Adult male Wistar rats weighing $250-300 \mathrm{~g}$ (3 months) were maintained in the Institute of Biological Science of the Federal University of Rio Grande at $22 \pm 2^{\circ} \mathrm{C}$, with a relative humidity of $50-60 \%$ under a 12 $12 \mathrm{~h}$ light-dark cycle with food (rodent feed, Nuvilab, Quimtia, Brazil) and water ad libitum. The experiments were performed after approval of the protocol by the Institutional Ethics Committee (approval number 
P021/2013) in agreement with the guidelines of the Brazilian National Council for Control of Animal Experimentation.

\section{Experimental protocol}

Animals were distributed in six groups and received the following treatments:

- Group I (saline; control group): saline ( $\mathrm{NaCl} 0.9 \%)(10 \mathrm{~mL} / \mathrm{kg})(\mathrm{n}=13)$

- Group II (diclofenac sodium; positive control group): diclofenac sodium (10 mg/kg) ( $\mathrm{n}=13)$

- Group III (CMC): carboxymethylcellulose (CMC) 0.5\% (10 mL/kg) $(\mathrm{n}=8)$

- Group IV ( $P$. boryanum biomass): lyophilized biomass of $P$. boryanum suspended in CMC $0.5 \%$ $(1000 \mathrm{mg} / \mathrm{kg})(\mathrm{n}=13)$

- Group V ( $P$. boryanum phenolic compounds): phenolic compounds extracted from lyophilized biomass of $P$. boryanum $(10 \mathrm{~mL} / \mathrm{kg})(\mathrm{n}=13)$

- Group VI ( $P$. boryanum extracellular): extracellular part of the cultivation of $P$. boryanum (10 $\mathrm{mL} / \mathrm{kg})(\mathrm{n}=13)$.

All the treatments were given intraperitoneally (i.p.) 30 min before the inducement of inflammation, except for diclofenac sodium which was given 90 min before.

\section{Carrageenan-induced rat paw edema}

Carrageenan induced paw edema assay was conducted according to the procedure first described by Winter and coauthors [18]. Each group of animals received subplantar administration of $100 \mu \mathrm{L}$ of carrageenan $1 \%(\mathrm{w} / \mathrm{v})$ in saline in the right hind paw and $100 \mu \mathrm{L}$ of saline in the left hind paw. The volume was measured with a hydroplethysmometer (Letica, Barcelona, Spain) immediately before (V0), 1, 2, and 3 $\mathrm{h}$ after the inducement of the inflammation by carrageenan (Vt). The assessment of paw volume was performed always by the same operator. The increase in paw volume was calculated by subtracting the initial paw volume (V0) to the paw volume measured at each time point. The percent inhibition in the increase of edema volume for each animal group was calculated by the following equation [19].

$$
\begin{aligned}
& \text { \% inhibition of edema } \\
& (\mathrm{Vt}-\mathrm{V} 0) \text { Control }
\end{aligned}=\quad[(\mathrm{Vt}-\mathrm{V0}) \text { Control }-(\mathrm{Vt}-\mathrm{V} 0) \text { Treated }] \times 100
$$

After the evaluation of edema, rats were killed by decapitation and hind paws we collected for the determination of cytokine levels. The liver was used for the measurement of oxidative stress parameters and the blood for comet assay and toxicological analysis.

\section{Tumor necrosis factor alpha (TNF- $\alpha$ ) and interleukin 1 (IL-1 $\beta$ ) levels}

The samples of rat's paw were pulverized (BioSpec, Bartlesville, USA) and homogenized (1:5, w/v) in PBS buffer (pH 7.4) added with Tween® $200.05 \%, \mathrm{NaCl} 0.4 \mathrm{M}$, BSA 0.5\%, EDTA $10 \mathrm{mM}$, and protease inhibitor cocktail (AMRE-M221-1M, Amresco, Solon, OH, USA). The homogenate was then centrifuged (3000 $\mathrm{x} \mathrm{g}, 10 \mathrm{~min}, 4^{\circ} \mathrm{C}$ ) and the supernatants were used to determine the content of TNF- $\alpha$ and IL-1 $\beta$ measured by Enzyme-linked Immunosorbent Assay (ELISA) using commercial kits according to manufacturer's instructions (R\&D Systems, Inc., Minneapolis, MN, USA). Protein content was quantified by the method of Lowry [20], using bovine serum albumin as standard. The results were expressed in pg per mg of protein.

\section{Oxidative stress markers}

\section{Tissue preparation}

For antioxidant capacity against peroxyl radicals (ACAP), reduced glutathione content, and Glutamatecysteine ligase activity assays, liver samples were homogenized $(1: 5, \mathrm{w} / \mathrm{v})$ in a Tris- $\mathrm{HCl}(100 \mathrm{mM}, \mathrm{pH} 7.75)$ buffer plus EDTA $(2 \mathrm{mM})$ and $\mathrm{MgCl} 2(5 \mathrm{mM})$. The homogenates were centrifuged $\left(10,000 \mathrm{~g}, 20 \mathrm{~min}, 4^{\circ} \mathrm{C}\right)$, and the supernatants employed. For lipid peroxidation measurement, liver samples were homogenized (1:10 $\mathrm{w} / \mathrm{v}$ ) in $1.15 \% \mathrm{KCl}$ containing $35 \mathrm{mM}$ of butylated hydroxytoluene (BHT). Homogenates were centrifuged for 10 min at $5,000 \mathrm{~g}, 4^{\circ} \mathrm{C}$, and the supernatants were used for the analysis. 


\section{Total antioxidant capacity against peroxyl radicals (ACAP)}

Total antioxidant capacity against peroxyl radicals was evaluated through reactive oxygen species (ROS) determination in tissue samples treated or not with a peroxyl radical generator (ABAP) according to Amado [21]. The nonfluorescent compound $\mathrm{H}_{2} \mathrm{DCF}$ is oxidized by ROS to the fluorescent compound DCF, which is detected in wavelengths of $488 \mathrm{~nm}$ for emission and $525 \mathrm{~nm}$ for excitation. The thermal decomposition of ABAP and ROS formation was monitored for $30 \mathrm{~min}$, with readings at every $5 \mathrm{~min}$ in a fluorescence microplate reader (Victor 2, Perkin Elmer, Waltham, MA, USA) at $37^{\circ} \mathrm{C}$. Data are expressed in terms of the reverse area, and the result is directly proportional to the antioxidant capacity of the tissue.

\section{Reduced glutathione content and glutamate-cysteine ligase activity}

Reduced glutathione (GSH) content and glutamate-cysteine ligase (GCL) activity were measured according to White and coauthors [22]. This method is based on the reaction of naphthalene -2,3dicarboxialdehyde (NDA) with GSH or $\gamma$-glutamylcysteine ( $\gamma-G C)$ to form cyclized products that are highly fluorescent. NDA-GSH fluorescence intensity was measured (528 nm emission/472 nm excitation) on a fluorescence microplate reader (Victor 2, Perkin Elmer, Waltham, MA, USA). GSH content was expressed in $\mu \mathrm{mol}$ per mg of protein and GCL activity in $\mu \mathrm{mol}$ of GCL $\mathrm{h}-1$ per mg of protein. The total protein content was measured in the supernatant with the Biuret method using a microplate absorbance reader (BioTek LX 800).

\section{Lipid peroxidation assay - Thiobarbituric Acid Reactive Substances (TBARS)}

Lipid peroxidation was determined by malondialdehyde reaction with thiobarbituric acid to give the chromophore compound which can be read spectrophotometrically at $553 \mathrm{~nm}$ [23]. Briefly, to $20 \mu \mathrm{L}$ of the homogenate a mixture of $20 \mu \mathrm{L}$ of $12.4 \mathrm{mM}$ Sodium Dodecyl sulfate (SDS), $150 \mu \mathrm{L}$ of $20 \%$ acetic acid, 150 $\mu \mathrm{L} 0.8 \%$ TBA, $31.5 \mu \mathrm{L}$ of water (Milli-Q®) and $20 \mu \mathrm{L} 67 \mathrm{mM} \mathrm{BHT}$ was added. The mixture was incubated at $95^{\circ} \mathrm{C}$ for $30 \mathrm{~min}$ and allowed to cool for $10 \mathrm{~min}$. Subsequently, $100 \mu \mathrm{L}$ water and $500 \mu \mathrm{L}$-butanol was added and the samples were centrifuged (3000 x g, $10 \mathrm{~min}$ ). The organic fraction was removed, and fluorescence was read at room temperature using a plate reader fluorometer (Victor 2, Perkin Elmer, Waltham, MA, USA) at $553 \mathrm{~nm}$ emission and $515 \mathrm{~nm}$ excitation. The concentration of peroxidized lipids was expressed in micromoles of malondialdehyde equivalents per gram of tissue ( $\mu$ mol MDA eq.g of tissue $\left.{ }^{-1}\right)$.

\section{Comet assay}

DNA damage assessment was performed via the alkaline comet assay using whole blood samples according to da Silva Júnior and coauthors [24]. Briefly, blood cell suspensions were mixed in 1\% agarose and spread on slides previously gelatinized with agarose. The slides were immersed in lysis buffer $(2.5 \mathrm{M}$ $\mathrm{NaCl}, 100 \mathrm{mM}$ EDTA, $10 \mathrm{~mL}$ Tris, Triton X-100, and Dimethyl Sulfoxide) for $240 \mathrm{~min}$ at $4^{\circ} \mathrm{C}$. Electrophoresis was conducted in a buffer $300 \mathrm{mM} \mathrm{NaOH}$ and $10 \mathrm{mM} \mathrm{Na}{ }_{2} \mathrm{EDTA}$ (pH 13.0), for $20 \mathrm{~min}(30 \mathrm{~V} / 300 \mathrm{~mA})$. The slides were stained with SYBR® Safe DNA gel stain (Carlsbad, CA, USA) and visualized in fluorescence microscopy connected through a black and white camera to image analysis system ImageJ for image analyses. 50 nucleoids were analyzed per animal. The results are presented as the percentage of DNA in the tail (tail DNA \%).

\section{Toxicological parameters}

Blood samples were centrifuged at $1,000 \mathrm{~g}$ for $10 \mathrm{~min}$ at room temperature, and the serum was separated for further analysis. Alanine Transaminase (ALT) and Aspartate Aminotransferase (AST) were determined by enzymatic assays, using diagnostic kits following the manufacturers' instructions (Labtest, Vista Alegre, MG, Brazil). The results were expressed in U/l.

\section{Statistical analysis}

All the values are expressed as mean \pm standard error of mean (SEM). Statistical significance was calculated by one-way analysis of variance (ANOVA) followed by Bonferroni post hoc test. $\mathrm{p}<0.05$ was considered to be statistically significant. 


\section{RESULTS}

\section{Characterization of free phenolic acids}

The free phenolic compounds extracted from the biomass of $P$. boryanum were screened with UFLC to maximize experimental efficacy. A total of two phenolic acids were identified in the samples: gallic and chlorogenic acid. For further investigation, a mass spectrum of the free phenolic compounds sample was performed. The scan shows the presence of molecular structures that match the molecular weight of gallic acid (168.9), chlorogenic acid (341), and fractions that may be the result of a not complete synthesis of the expected compounds protocatechuic acid (178) and vanillic acid (128) as shown in Figure 1.

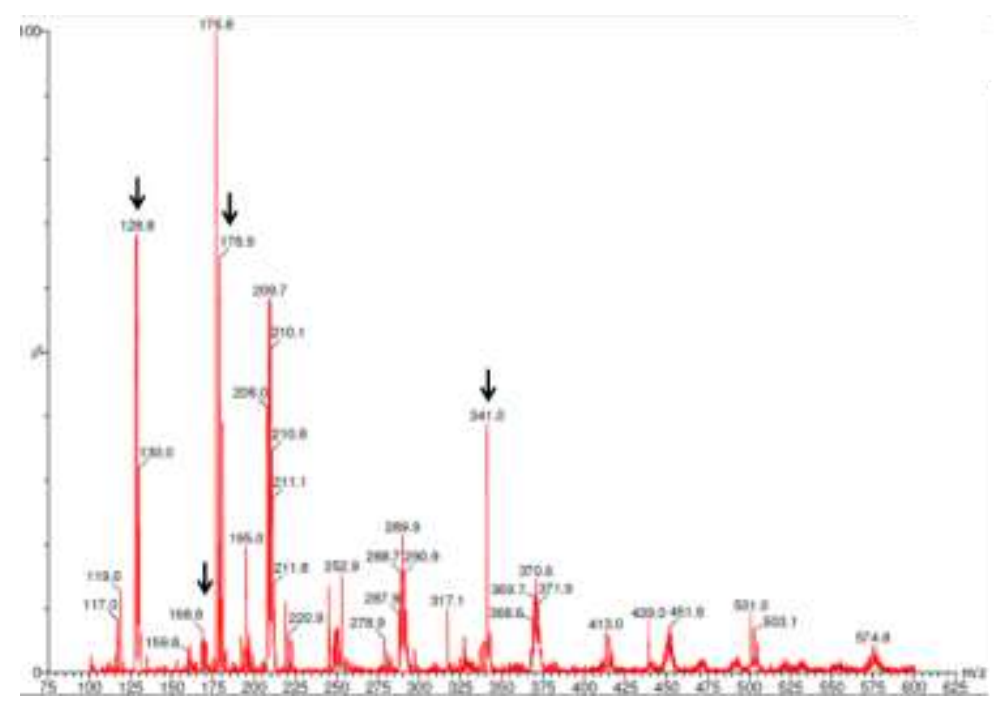

Figure 1. MS/MS spectra of free phenolic compounds extracted from $P$. boryanum.

\section{Anti-inflammatory activity}

Intraplantar injection of carrageenan induced an increase in the rat paw volume, indicating the induction of edema. The treatment with $P$. boryanum biomass and phenolic compounds significantly reduced the edema from the first hour of induction. The CMC used as a vehicle for $P$. boryanum biomass caused a significant reduction in edema, around $32 \%$ (third our). Then, the maximum effect of the $P$. boryanum biomass can be considered about $63 \%$, considering that part of it comes from the vehicle. The extracellular extract was less effective than the others, showing a reduction in edema only after the second hour and with a maximum effect of $45 \%$. Therefore, the greatest anti-oedematogenic effect was obtained with the phenolic compounds extracted from the microalga $P$. boryanum, $86 \%$ in the third hour. The positive control, diclofenac sodium, significantly reduced the paw edema after 2 hours of induction (Table 1).

Carrageenan induced the production of pro-inflammatory cytokines, IL-1 $\beta$ and TNF- $\alpha$, in rats paw indicating an inflammatory process. All the treatments significantly reduced the cytokine levels when compared to the saline group, showing the anti-inflammatory effect of $P$. boryanum extracts. The CMC also reduced the levels of cytokines, similarly to that observed in the paw edema. As expected, the positive control reduced the levels of IL-1 $\beta$ and TNF- $\alpha$ (Figure 2). 
Table 1. Effects of $P$. boryanum extracts on paw edema induced by carrageenan in rats.

\begin{tabular}{|c|c|c|c|c|c|c|}
\hline \multirow[b]{2}{*}{ Treatment } & \multicolumn{2}{|l|}{$1 \mathrm{~h}$} & \multicolumn{2}{|l|}{$2 h$} & \multicolumn{2}{|c|}{$3 \mathrm{~h}$} \\
\hline & $\begin{array}{c}\Delta \text { Paw edema } \\
(\mathrm{mL})\end{array}$ & $\begin{array}{c}\% \\
\text { inhibition }\end{array}$ & $\begin{array}{c}\Delta \text { Paw edema } \\
(\mathrm{mL})\end{array}$ & $\begin{array}{c}\% \\
\text { inhibition }\end{array}$ & $\begin{array}{c}\Delta \text { Paw edema } \\
(\mathrm{mL})\end{array}$ & $\%$ inhibition \\
\hline Saline & $0.16 \pm 0.03$ & & $0.64 \pm 0.06$ & & $0.81 \pm 0.06$ & \\
\hline $\begin{array}{l}\text { Diclofenac } \\
\text { Sodium }\end{array}$ & $0.08 \pm 0.02$ & 53 & $0.15 \pm 0.02^{* * *}$ & 77 & $0.26 \pm 0.03^{\star * *}$ & 68 \\
\hline CMC & $0.13 \pm 0.03$ & 19 & $0.42 \pm 0.05^{\star *}$ & 34 & $0.55 \pm 0.05^{\star *}$ & 32 \\
\hline $\begin{array}{l}\text { P.boryanum } \\
\text { biomass }\end{array}$ & $0.02 \pm 0.01^{* * *} \#$ & 85 & $0.03 \pm 0.01^{* * *} \# \# \#$ & 96 & $0.04 \pm 0.01^{* * *} \# \# \#$ & 95 \\
\hline $\begin{array}{l}\text { P. boryanum } \\
\text { phenolic } \\
\text { compounds }\end{array}$ & $0.06 \pm 0.00^{*}$ & 63 & $0.11 \pm 0.02^{* * *}$ & 83 & $0.12 \pm 0.02^{* * *}$ & 86 \\
\hline $\begin{array}{l}\text { P. boryanum } \\
\text { extracellular }\end{array}$ & $0.18 \pm 0.03$ & 0 & $0.45 \pm 0.05^{\star \star}$ & 30 & $0.45 \pm 0.06^{\star * \star}$ & 45 \\
\hline
\end{tabular}

Values of the delta of the edema are expressed as mean \pm SEM $(n=8-13) .{ }^{*} p<0.05 ;{ }^{* *} p<0.01 ;{ }^{* * *} p<0.001$ indicates the difference when compared to saline group; $\# p<0.05$; \#\#\# $p<0.001$ indicates the difference when compared to CMC group (one-way ANOVA followed by the Bonferroni post hoc test).
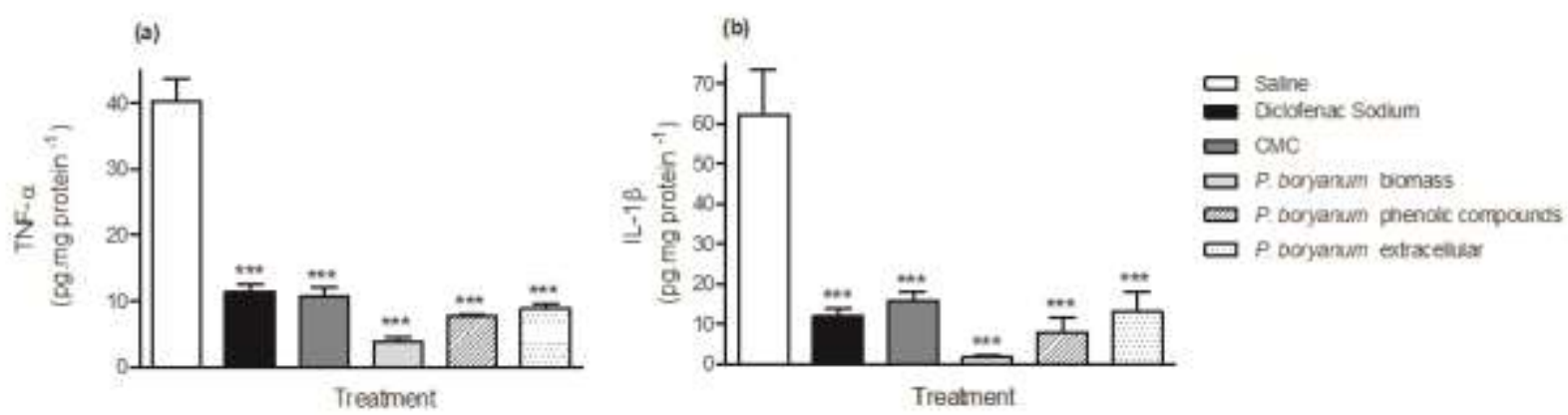

Figure 2. Effects of $P$. boryanum extracts on carrageenan-induced cytokine production, TNF- $\alpha(a)$ and IL-1 $\beta$ (b), in rats hind paws. Rats were treated by intraperitoneal pathway with saline, diclofenac sodium (10 mg/kg); Carboximetilculose $0.5 \%$ (CMC, $10 \mathrm{~mL} / \mathrm{kg}), P$. boryanum biomass $(1000 \mathrm{mg} / \mathrm{kg}), P$. boryanum extracellular extract $(10 \mathrm{~mL} / \mathrm{kg})$ or $P$. boryanum phenolic compounds extract $(10 \mathrm{~mL} / \mathrm{kg})$. The inflammation was induced by the administration of carrageenan $1 \%(w / v)$ in the right hind paw. Each bar represents the mean \pm SEM $(n=4){ }^{* * *} p<0.001$ indicates the difference when compared to saline group (one-way ANOVA followed by the Bonferroni post hoc test)

\section{Oxidative stress and toxicological parameters}

The results of oxidative stress analysis performed in the liver are presented in Table 2. All the experimental groups show similar GSH levels and GCL, the limiting enzyme for the synthesis of GSH, activity. Interestingly, the rats treated with the extracellular extract of $P$. boryanum showed an increased total antioxidant capacity against peroxyl radicals when compared to the control group (saline) $(p<0.01)$. The oxidative damage to lipids was measured through the TBARS assay. The liver lipid peroxidation was significantly reduced after the treatment with $P$. boryanum biomass when compared to the saline group $(p<0.05)$. The DNA damage was evaluated by the comet assay, as also demonstrated in Table 2. Our data show that the different treatments did not affect the percentage of DNA in the tail. Moreover, the acute treatment with P. boryanum extracts did not modify ALT and AST enzymes in the peripheral blood from the rats (Table 3 ), demonstrating the normal function of the liver after the test. 
Table 2. Effects of $P$. boryanum extracts on the Total Antioxidant Capacity Against Peroxyl radicals (ACAP), Glutathione Reduced Content (GSH), Glutamate-Cysteine Ligase Activity (GCL) and Thiobarbituric Acid Reactive Substances (TBARS), in rat livers, and DNA damage in blood cells.

\begin{tabular}{|c|c|c|c|c|c|}
\hline Treatment & $\begin{array}{c}\text { ACAP } \\
\text { (Inverse of } \\
\text { relative area) }\end{array}$ & $\begin{array}{c}\text { GSH } \\
(\mu \mathrm{mol} . \mathrm{mg} \text { protein } \\
\text { 1) }\end{array}$ & $\begin{array}{c}\text { GCL activity } \\
\left(\mu \text { mol.mg } h^{-1} \text { of }\right. \\
\left.\text { protein }^{-1}\right)\end{array}$ & $\begin{array}{c}\text { TBARS } \\
(\mu \mathrm{mol} \text { MDAeq. } g \text { of } \\
\left.\text { tissue }^{-1}\right)\end{array}$ & $\begin{array}{c}\text { Tail DNA } \\
(\%)\end{array}$ \\
\hline Saline & $0.053 \pm 0.004$ & $205.22 \pm 55.68$ & $1608.30 \pm 30.17$ & $0.046 \pm 0.002$ & $2.99 \pm 0.41$ \\
\hline $\begin{array}{l}\text { Diclofenac } \\
\text { Sodium }\end{array}$ & $0.045 \pm 0.002$ & $263.98 \pm 54.81$ & $1563.34 \pm 22.39$ & $0.041 \pm 0.004$ & $2.98 \pm 0.32$ \\
\hline $\mathrm{CMC}$ & $0.042 \pm 0.001$ & $243.66 \pm 54.13$ & $1452.74 \pm 79.75$ & $0.043 \pm 0.003$ & $2.13 \pm 0.30$ \\
\hline $\begin{array}{l}\text { P.boryanum } \\
\text { biomass }\end{array}$ & $0.046 \pm 0.002$ & $119.88 \pm 25.68$ & $1378.16 \pm 67.88$ & $0.032 \pm 0.003^{*}$ & $1.87 \pm 0.27$ \\
\hline $\begin{array}{l}P . \text { boryanum } \\
\text { phenolic } \\
\text { compounds }\end{array}$ & $0.046 \pm 0.002$ & $260.66 \pm 54.10$ & $1510.91 \pm 36.95$ & $0.049 \pm 0.001$ & $2.03 \pm 0.16$ \\
\hline $\begin{array}{l}\text { P. boryanum } \\
\text { extracellular }\end{array}$ & $0.071 \pm 0.007^{\star}$ & $354.78 \pm 54.10$ & $1711.87 \pm 96.32$ & $0.042 \pm 0.003$ & $1.88 \pm 0.27$ \\
\hline
\end{tabular}

Values are expressed as mean \pm SEM $(n=4-5)$. ${ }^{*} \mathrm{p}<0.05$ indicates the difference when compared to saline group (one-way ANOVA followed by the Bonferroni post hoc test).

Table 3. Effects of $P$. boryanum extracts on hepatic transaminases in the blood of rats.

\begin{tabular}{lcc}
\hline \multicolumn{1}{c}{ Treatment } & ALT (U/L) & AST (U/L) \\
\hline Saline & $180.90 \pm 17.41$ & $34.41 \pm 6.02$ \\
Diclofenac Sodium & $192.43 \pm 21.04$ & $33.33 \pm 2.64$ \\
CMC & $127.02 \pm 4.74$ & $33.17 \pm 1.81$ \\
P.boryanum biomass & $154.14 \pm 21.43$ & $35.63 \pm 2.67$ \\
P. boryanum phenolic compounds & $164.13 \pm 30.93$ & $53.43 \pm 7.05$ \\
$P$. boryanum extracellular & $127.53 \pm 13.02$ & $51.62 \pm 1.10$ \\
\hline
\end{tabular}

Values are expressed as mean \pm SEM $(n=4)$. 


\section{DISCUSSION}

The evaluation of new pharmacological drugs obtained from natural products has been of great interest in the pharmaceutical field [25]. Studies have emerged highlighting the potential of microalgae extracts as sources of compounds with anti-inflammatory properties [26-28]. The results of the current study demonstrate that different extracts from the microalga $P$. boryanum displays potent anti-edematogenic properties and reduces the cytokines levels in rats submitted to carrageenan induced hind paw edema. Interestingly, when oxidative stress parameters were evaluated, it was found that biomass reduced lipoperoxidation in the liver of rats while the extracellular extract increased the total antioxidant capacity in this organ.

Carrageenan induced hind paw edema is a standard experimental model of acute inflammation widely used for the evaluation of assessing the anti-inflammatory properties of new drugs and natural products $[6,29,30]$. The inflammation induced by carrageenan is acute, non-immune, well-known, and highly reproducible. It is characterized by an increase of vascular permeability and cell infiltration, mainly neutrophils, and the production of proinflammatory mediators, such as cytokines, chemokines, and ROS [31,32]. Proinflammatory cytokines, such as TNF- $\alpha$ and IL-1 $\beta$ are implicated in the pathogenesis of acute inflammation and are responsible for the production of acute-phase proteins. These cytokines are released mainly from monocytes and macrophages at the inflammatory sites [33,34].

Our results show that all the $P$. boryanum extracts tested exhibits anti-oedematous properties and were able to reduce the levels of cytokines, TNF- $\alpha$, and IL-1 $\beta$. This is in accordance with similar studies with red and green algae in experimental inflammation models $[6,10]$. The best anti-edematogenic results were observed after treatment with the extracted phenolic compounds of $P$. boryanum. The chemical analysis demonstrated that this fraction is rich in gallic acid, chlorogenic acid and probably protocatechuic acid and vanillic acid. Recently, in a previous study, we quantified the phenolic compounds content in $P$. boryanum biomass cultivated in the same media and evidenced its antioxidant activity in vitro [13]. Literature data show that phenolic compounds from different sources have anti-edematogenic effects in rodents inflammation models [35-37]. The mechanisms of anti-inflammatory activity of phenolic compounds can involve the modulation of immunity by interfering with immune cell regulation, synthesis of proinflammatory cytokines, and pro-inflammatory gene expression. Moreover, their antioxidant properties can contribute to antiinflammatory activity since the overproduction of ROS prompt tissue injury that might initiate the inflammatory process [38].

Our data show that the levels of two pro-inflammatory cytokines were reduced after treatment with all tested extracts. This indicates that although phenolic extract of $P$. boryanum has been more effective in reducing edema, biomass, and extracellular extracts also present anti-inflammatory activity. It is worth noting that, although they have not been studied, the lyophilized biomass of $P$. boryanum may contain other phenolic compounds in addition to protein and lipid components. Some studies have already shown that lipid metabolites found in microalgae biomass, for example from Chlamydomonas debaryana, are antiinflammatory and capable of reducing TNF- $\alpha$ levels [39,40].

We also explored the effects of the extracellular extract of $P$. boryanum. This soluble part of microalgae is normally rich in polysaccharides, as previously demonstrated for other species [41]. The presence of polysaccharides has already been described to contribute to the anti-inflammatory activity of different species of microalga [42]. Microalga derived polysaccharides can reduce the neutrophil infiltration [43], decrease proinflammatory cytokines [44,45], increase nitric oxide [44], and modulates antioxidant defenses [46].

In addition to anti-inflammatory activity, we investigated the effects of different extracts on oxidative stress parameters in the liver of animals. The oxidative damage to lipids was measured by TBARS assay, which identifies the presence of malondialdehyde (MDA) which is one of the end products of lipid peroxidation [47]. The $P$. boryanum biomass significantly reduced the TBARS levels. The presence of antioxidant substances in the microalgae biomass, such as phenolic acids and others, can neutralize reactive species of oxygen and nitrogen, reducing the lipid oxidative damage. Corroborating this result, recently, we demonstrated the antioxidant activity in vitro from $P$. boryanum against DPPH and ABTS radicals [13].

The total antioxidant capacity against peroxyl radicals is a broad assay. The non-enzymatic lowmolecular-weight scavengers, GSH accounts for part of the total scavenging capacity towards peroxyl radicals. GSH is a tripeptide containing cysteine which plays important roles in human cells, especially as an antioxidant agent. The GSH maintains the thiols (-SH) groups of proteins, reducing disulfide bonds (-SS-) induced by oxidative stress and neutralize free radicals. Therefore, the intracellular concentration of GSH is an indicator of the ability of the cell to maintain homeostasis by neutralizing oxidizing agents [22]. According 
to our results, the treatment with different extracts of $P$. boryanum did not affect the levels of GSH, neither the activity of its synthesis enzyme GCL. However, $P$. boryanum extracellular extract enhanced the total antioxidant capacity without affecting the GSH content. As we previously described, this extract is rich in polysaccharides that can modulate the antioxidant defenses, contributing to the improvement of the tissue antioxidant capacity [46].

In addition, some parameters of the safety of $P$. boryanum were evaluated. The genotoxic effects were determined through the comet assay, a sensitive method to detect single- and double-stranded DNA breaks [48]. Our results revealed that the acute intraperitoneal administration of $P$. boryanum extracts in rats did not cause genotoxic effects. Moreover, the absence of alteration in liver enzymes ALT and AST is in accordance with other studies on intraperitoneal administrations of algae $[10,29]$. Corroborating this data, we previously demonstrated that acute administration of lyophilized microalgal biomass of $P$. boryanum showed no significant signs of toxicity at doses of 300 and $2000 \mathrm{mg} / \mathrm{kg}$, and is therefore considered safe in accordance with the classification OECD in category 5 [14].

In summary, our results demonstrated that $P$. boryanum and its fractions have anti-inflammatory effect in the rat model of inflammation, by reducing the paw oedema and cytokines production. This indicates that $P$. boryanum represents an important source of bioactive compounds that presents a potential application in the treatment of inflammatory diseases.

Funding: This study was partially funded by the Coordenação de Aperfeiçoamento de Pessoal de Nível Superior Brasil (CAPES) - Finance Code 001.

Conflicts of Interest: The authors declare no conflict of interest.

\section{REFERENCES}

1. Sasso S, Pohnert G, Lohr M, Mittag M, Hertweck C. Microalgae in the postgenomic era: a blooming reservoir for new natural products. FEMS Microbiol Rev. 2012 Jul;36(4):761-85.

2. Ciferri O. Spirulina, the edible microorganism. Microbiol Rev. 1983;47(4):551-78.

3. Colla LM, Furlong EB, Costa JAV. Antioxidant properties of Spirulina (Arthospira) platensis cultivated under different temperatures and nitrogen regimes. Brazilian Arch Biol Technol. 2007;50(1):161-7.

4. Costa JAV, de Morais MG. The role of biochemical engineering in the production of biofuels from microalgae. Bioresour Technol. 2011 Jan;102(1):2-9.

5. Leu S, Boussiba S. Advances in the Production of High-Value Products by Microalgae. Ind Biotechnol. 2014 Jun;10(3):169-83.

6. Pereira JG, Mesquita JX, Aragão KS, Franco ÁX, Souza MHLP, Brito T V., et al. Polysaccharides isolated from Digenea simplex inhibit inflammatory and nociceptive responses. Carbohydr Polym. 2014 Aug;108:17-25.

7. Sharma B, Kim H, Rhyu D. Caulerpa lentillifera extract ameliorates insulin resistance and regulates glucose metabolism in C57BL/KsJ-db/db mice via PI3K/AKT signaling pathway in myocytes. J Transl Med. 2015;13(1):62.

8. Yeh C-C, Tseng C-N, Yang J-I, Huang H-W, Fang Y, Tang J-Y, et al. Antiproliferation and Induction of Apoptosis in Ca9-22 Oral Cancer Cells by Ethanolic Extract of Gracilaria tenuistipitata. Molecules. 2012 Sep 11;17(9):1091627.

9. Ávila-Román J, Talero E, Rodríguez-Luna A, García-Mauriño S, Motilva V. Anti-inflammatory effects of an oxylipincontaining lyophilised biomass from a microalga in a murine recurrent colitis model. $\mathrm{Br} \mathrm{J}$ Nutr. $2016 \mathrm{Dec}$ 28;116(12):2044-52.

10. Joventino IP, Alves HGR, Neves LC, Pinheiro-Joventino F, Leal LKAM, Neves SA, et al. The Microalga Spirulina platensis Presents Anti-inflammatory Action as well as Hypoglycemic and Hypolipidemic Properties in Diabetic Rats. J Complement Integr Med. 2012 Jan 10;9(1).

11. Talero E, García-Mauriño S, Ávila-Román J, Rodríguez-Luna A, Alcaide A, Motilva V. Bioactive compounds isolated from microalgae in chronic inflammation and cancer. Mar Drugs. 2015;13(10):6152-209.

12. Wu Q, Liu L, Miron A, Klímová B, Wan D, Kuča K. The antioxidant, immunomodulatory, and anti-inflammatory activities of Spirulina: an overview. Arch Toxicol. 2016 Aug 3;90(8):1817-40.

13. Corrêa da Silva MG, Pires Ferreira S, Dora CL, Hort MA, Giroldo D, Prates DF, et al. Phenolic compounds and antioxidant capacity of Pediastrum boryanum (Chlorococcales) biomass. Int J Environ Health Res. 2020 Mar 23;00(00):1-13.

14. Fonseca AF, Corrêa da Silva MG, da Silva MMA, Almeida KA, Tavella RA, Silva-Júnior FMR, et al. Evaluation of acute toxicity of the microalgae Pediastrum boryanum. Vittalle. 2016;28:90-102.

15. Guillard RRL, Lorenzen CJ. Yellow-gree algae with chlorophylidde C. J Phycol. 1972;8(1):10-4. 
16. Souza MM de, Recart VM, da Rocha M, Cipolatti EP, Badiale-Furlong E. Study on the extracting conditions of phenolic compounds from onion ( Allium cepa L .). Rev do Inst Oswaldo Cruz. 2009;68(2):192-200.

17. Pagnussatt FA, Kupski L, Darley FT, Filoda PF, Ponte ÉM Del, Garda-Buffon J, et al. Fusarium graminearum growth inhibition mechanism using phenolic compounds from Spirulina sp. Ciência e Tecnol Aliment. 2013 Feb;33:75-80.

18. Winter CA, Risley EA, Nuss GW. Carrageenin-Induced Edema in Hind Paw of the Rat as an Assay for Antiinflammatory Drugs. Exp Biol Med. 1962 Dec 1;111(3):544-7.

19. Ananthi S, Raghavendran HRB, Sunil AG, Gayathri V, Ramakrishnan G, Vasanthi HR. In vitro antioxidant and in vivo anti-inflammatory potential of crude polysaccharide from Turbinaria ornata (Marine Brown Alga). Food Chem Toxicol. 2010 Jan;48(1):187-92.

20. Lowry OH, Rosenbrough NJ, Farr AL, Randall RJ. Protein measurement with the folin phenol reagent. J Biol Chem. 1951;193(1):265-75.

21. Amado LL, Garcia ML, Ramos PB, Freitas RF, Zafalon B, Ferreira JLR, et al. A method to measure total antioxidant capacity against peroxyl radicals in aquatic organisms: Application to evaluate microcystins toxicity. Sci Total Environ. 2009 Mar;407(6):2115-23.

22. White CC, Viernes H, Krejsa CM, Botta D, Kavanagh TJ. Fluorescence-based microtiter plate assay for glutamatecysteine ligase activity. Anal Biochem. 2003 Jul;318(2):175-80.

23. Oakes KD, Van Der Kraak GJ. Utility of the TBARS assay in detecting oxidative stress in white sucker (Catostomus commersoni) populations exposed to pulp mill effluent. Aquat Toxicol. 2003;63(4):447-63.

24. Da Silva Júnior FMR, Silva PF, Garcia EM, Klein RD, Peraza-Cardoso G, Baisch PR, et al. Toxic effects of the ingestion of water-soluble elements found in soil under the atmospheric influence of an industrial complex. Environ Geochem Health. 2013; 35(3):317-31.

25. Pan M-H, Lai C-S, Ho C-T. Anti-inflammatory activity of natural dietary flavonoids. Food Funct. 2010;1(1):15.

26. Suh S-S, Hong J-M, Kim EJ, Jung SW, Chae H, Kim JE, et al. Antarctic freshwater microalga, Chloromonas reticulata , suppresses inflammation and carcinogenesis. Int J Med Sci. 2019;16(2):189-97.

27. Guzmán S, Gato A, Calleja JM. Antiinflammatory, analgesic and free radical scavenging activities of the marine microalgae Chlorella stigmatophora and Phaeodactylum tricornutum. Phyther Res. 2001;15(3):224-30.

28. Pak W, Takayama F, Mine M, Nakamoto K, Kodo Y, Mankura M, et al. Anti-oxidative and anti-inflammatory effects of spirulina on rat model of non-alcoholic steatohepatitis. J Clin Biochem Nutr. 2012;51(3):227-34.

29. Rodrigues JAG, Vanderlei EDSO, Silva LMCM, de Araújo IWF, de Queiroz INL, de Paula GA, et al. Antinociceptive and anti-inflammatory activities of a sulfated polysaccharide isolated from the green seaweed Caulerpa cupressoides. Pharmacol Reports. 2012 Mar;64(2):282-92.

30. Vanderlei ESO, Patoilo KKNR, Lima NA, Lima APS, Rodrigues JAG, Silva LMCM, et al. Antinociceptive and antiinflammatory activities of lectin from the marine green alga Caulerpa cupressoides. Int Immunopharmacol. 2010 Sep;10(9):1113-8.

31. Di Rosa M, Giroud JP, Willoughby DA. Studies of the mediators of the acute inflammatory response induced in rats in different sites by carrageenan and turpentine. J Pathol. 1971 May;104(1):15-29.

32. Sugishita E, Amagaya S, Ogihara Y. Anti-inflammatory testing methods: Comparative evaluation of mice and rats. J Pharmacobiodyn. 1981;4(8):565-75.

33. Kushner I. Regulation of the Acute Phase Response by Cytokines. Perspect Biol Med. 1993;36(4):611-22.

34. Gabay C. Interleukin-6 and chronic inflammation. Arthritis Res Ther. 2006;8(Suppl 2):S3.

35. Peng J, Hu T, Li J, Du J, Zhu K, Cheng B, et al. Shepherd's Purse Polyphenols Exert Its Anti-Inflammatory and Antioxidative Effects Associated with Suppressing MAPK and NF- K B Pathways and Heme Oxygenase-1 Activation. Oxid Med Cell Longev. 2019 Jan 13;2019:1-14.

36. Hegazi NM, Sobeh M, Rezq S, El-Raey MA, Dmirieh M, El-Shazly AM, et al. Characterization of phenolic compounds from Eugenia supra-axillaris leaf extract using HPLC-PDA-MS/MS and its antioxidant, antiinflammatory, antipyretic and pain killing activities in vivo. Sci Rep. 2019 Dec 31;9(1):11122.

37. Zouari Bouassida K, Makni S, Tounsi A, Jlaiel L, Trigui M, Tounsi S. Effects of Juniperus phoenicea Hydroalcoholic Extract on Inflammatory Mediators and Oxidative Stress Markers in Carrageenan-Induced Paw Oedema in Mice. Biomed Res Int. 2018 Jul 9;2018:1-11.

38. Yahfoufi N, Alsadi N, Jambi M, Matar C. The Immunomodulatory and Anti-Inflammatory Role of Polyphenols. Nutrients. 2018 Nov 2;10(11):1618.

39. De los Reyes C, Ávila-Román J, Ortega MJ, de la Jara A, García-Mauriño S, Motilva V, et al. Oxylipins from the microalgae Chlamydomonas debaryana and Nannochloropsis gaditana and their activity as TNF- $\alpha$ inhibitors. Phytochemistry. 2014 Jun;102:152-61.

40. Ávila-Román J, Talero E, Alcaide A, De Los Reyes C, Zubía E, García-Mauriño S, et al. Preventive effect of the microalga Chlamydomonas debaryana on the acute phase of experimental colitis in rats. $\mathrm{Br} J$ Nutr. 2014;112(7):1055-64. 
41. Da Silva Maria L, Vieira AAH, Giroldo D. Phytoplankton from subtropical ponds: Growth parameters, carbohydrate production, and polysaccharide composition of three chlorophytes. In: Ponds: Formation, Characteristics, and Uses. New York: Nova Science Publishers; 2011. p. 103-22.

42. De Jesus Raposo MF, De Morais RMSC, De Morais AMMB. Bioactivity and applications of sulphated polysaccharides from marine microalgae. Mar Drugs. 2013;11(1):233-52.

43. Silva-Leite KES, Girão DKFB, de Freitas Pires A, Assreuy AMS, de Moraes PAF, Cunha AP, et al. Ximenia americana heteropolysaccharides ameliorate inflammation and visceral hypernociception in murine caeruleininduced acute pancreatitis: Involvement of CB2 receptors. Biomed Pharmacother. 2018 Oct;106(July):1317-24.

44. De Brito TV, Prudêncio RDS, Sales AB, Vieira Júnior FDC, Candeira SJN, Franco ÁX, et al. Anti-inflammatory effect of a sulphated polysaccharide fraction extracted from the red algae Hypnea musciformis via the suppression of neutrophil migration by the nitric oxide signalling pathway. J Pharm Pharmacol. 2013;65(5):724-33.

45. Miao X-P, Sun X-N, Cui L-J, Cao Q-F, Zhuang G-F, Deng T-Z, et al. Suppressive effect of pectic polysaccharides extracted from Rauwolfia verticillata (Lour.) Baill.var.hainanensis Tsiang on inflammation by regulation of NF- $\mathrm{K}$ pathway and interleukin-17 in mice with dextran sulphatesodium-induced ulcerative colitis. Asian Pac J Trop Med. 2015 Feb;8(2):147-52.

46. Subash A, Veeraraghavan G, Sali VK, Bhardwaj M, Vasanthi HR. Attenuation of inflammation by marine algae Turbinaria ornata in cotton pellet induced granuloma mediated by fucoidan like sulphated polysaccharide. Carbohydr Polym. 2016 Oct;151:1261-8.

47. Hermes-Lima M. Oxygen in Biology and Biochemistry: Role of Free Radicals. In: Functional Metabolism. Hoboken, NJ, USA: John Wiley \& Sons, Inc.; 2005. p. 319-68.

48. Vandghanooni S, Eskandani M. Comet assay: A method to evaluate genotoxicity of nano-drug delivery system. Biolmpacts. 2011;1(2):87-97.

(c) 2021 by the authors. Submitted for possible open access publication under the terms and conditions of the Creative Commons Attribution (CC BY NC) license (https://creativecommons.org/licenses/by-nc/4.0/). 